\title{
Máscaras e faces da violência
}

\author{
Masks and faces of violence
}

\begin{abstract}
Roberto Gomes*
* Analista didata, membro efetivo da Sociedade Psicanalítica de Porto Alegre, Porto Alege, RS. Médico psiquiatra. E-mail: roberto.gomes@terra.com.br.
\end{abstract}

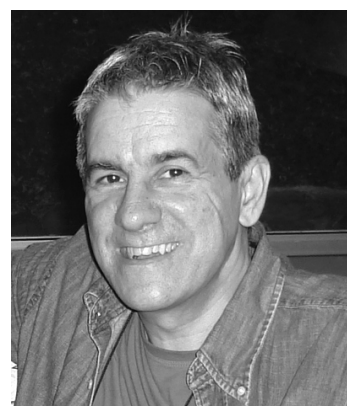

O tema da violência esteve presente já nos primórdios da psicanálise e culmina com a concepção do complexo de Édipo, tendo o assassinato do pai se tornado o paradigma do ato violento na psicanálise clássica (temos aqui a violência no contexto familiar).

$\mathrm{O}$ texto em que Freud discute a violência com maior amplitude é sua "Carta a Einstein" (1933). Como atenuante para as situações de violência, ele destaca o reconhecimento de uma identidade de interesses entre os grupos e o surgimento de vínculos emocionais (Freud estabelece o contexto de aplicação da psicanálise à violência social).

Se Freud socorreu-se de Empédocles para, em 1920, formular o que acontece além do princípio do prazer $\mathrm{e}$ configurar as bases do conflito humano sobre a ambivalência entre Eros e Tânatos, e se também formulou uma complexa relação entre esses conflitos ambivalentes e os grupos sociais humanos em Totem e Tabu e Psicologia de Grupo socorrendo-se de Darwin e Le Bon, que formulações temos hoje que superem esses princípios fundamentais? Em minha opinião, até o momento nada parece haver que as supere ${ }^{1}$.

As manifestações sobre o filme Tropa de Elite e os "A pedido" com retratos falados publicados nos jornais oferecendo recompensa pela denúncia de bandidos, bem nos moldes dos "Procura-se" dos faroestes americanos, extravasam o sentimento da sociedade diante da violência e nos pressionam a procurar soluções que, na verdade, terão efeito apenas a médio e longo prazo.

Com efeito, tanto as pesquisas que aproximam as teorias biológicas modernas da psicanálise quanto as concepções da psicanálise aplicada às teorias sociais acenam com hipóteses verificáveis em tempo incerto.

Além disso, a implementação de projetos, programas e pesquisas sobre a violência enfrenta obstáculos que atrasam a demonstração de sua eficácia. $\mathrm{O}$ recente debate em torno da pesquisa em internos da ex-FEBEM, amplamente divulgado na mídia, atesta como os avanços e retrocessos, Eros e Tânatos, verdade e mentira, confundem-se e confundem nossas políticas.

Não se trata de ser apenas pessimista diante de um tema - a violência - que suscita esse sentimento com muita força, mas de fixar nosso olhar em uma realidade que tende a nos cegar, ou seja, o fato de que nós, seres humanos, somos complicados, contraditórios e cruéis e que nos incomoda saber que isso não vai mudar nunca ${ }^{2}$.

A violência não é um flagelo apenas dos dias atuais. Saramago, no seu livro O Evangelho Segundo Jesus Cristo, repassa a violência cometida desde priscas eras em nome de Deus e de causas pretensamente civilizadoras e humanitárias. No diálogo com Deus, o Pastor previne Jesus do quanto de morte e sofrimento iria custar sua vitória sobre os outros deuses. Seguemse, então, por longas seis ou sete páginas, numa ladainha escabrosa, em ordem alfabética, de crucificados a esfolados, todas as violências hoje imagináveis, além de outras que só no futuro serão conhecidas.

Aprochegando-me a este nosso século recém-findo, deparei-me com as estatísticas das mortes havidas na Primeira e na Segunda Guerra Mundial. Somando-se a elas as pessoas mortas em revoluções, guerras civis e governos absolutistas no século XX, teremos um recorde histórico.

Este foi um século de violência. E de horror. E de medo. Os Tempos Sombrios de Brecht: "Realmente, vivemos tempos sombrios! A inocência é loucura. Uma fronte sem rugas denota insensibilidade. Aquele que ri ainda não recebeu a terrível notícia que está para chegar."

Quem interpreta corretamente este horror relacionando-o com o cotidiano de nossos dias é Renato Janine Ribeiro, filósofo, professor titular de Ética e Filosofia Política na Universidade de São Paulo (USP). Em dois artigos, "Razão e Sensibilidade" e "Dizer o Indizível", extravasa sua indignação e horror diante da violência contra o menino João Hélio, no que denomina crime bárbaro e violento contra a humanidade. Afirma não ver diferença entre a crueldade desses bandidos e a dos nazistas: "Isto é escrever sobre o horror em estado puro. Como pensar no sofrimento da criança?".

Pensar no nazismo entre nós e dentro de nós - esta é a idéia mais original do artigo - remete aos artigos sobre o tema publicados por psicanalistas: a comparação do horror das organizações patológicas internas com a máfia ou o nazismo.

Ao encarar este mundo devastado e de aflições típico do limiar da posição depressiva, devemos levar em 
consideração a história das tentativas de superá-lo, sem incorrermos na loucura da inocência. Afinal, como continua Brecht: "Que tempos são estes, em que é quase um delito falar de coisas inocentes, pois isso implica silenciar sobre tantos horrores?".

Creio que cabe lembrar a história da lenda do deus tebano Osíris, relacionada a antecedentes em que grassavam a violência e a selvageria. A condição para Osíris suceder seu pai era retirar os egípcios da barbárie, para o que era preciso, entre outras coisas, suprimir o canibalismo. Osíris editou leis que obrigavam os homens a respeitar princípios de convivência, em vez de fundamentar suas demandas e ações de acordo com seus caprichos e a violência. A persuasão, a razão e a música foram os principais instrumentos de sua missão civilizadora, que se estendeu por toda a terra. Dizem as más línguas que seu sucesso deve ser realmente atribuído a Ísis, que lhe ofereceu l'orge (planta cultivada como cereal e utilizada na produção de miçangas) e du blé (o trigo), cereal para produzir farinha de pão, como o trigo negro sarraceno.

Nessa mesma linha, mais recentemente, Luc Ferry, em conferência proferida no seminário Fronteiras do Pensamento, em Porto Alegre, traçou relações entre o bem-viver, a educação dos filhos e a filosofia. Ele considera que os pais - e aqui ele passa da esfera pública para a privada - podem se considerar realizados como educadores quando conseguem transmitir aos seus filhos três pontos fundamentais: o amor, pois nenhuma criança é feliz sem ser amada; a lei, que é a que ensina o limite em relação ao outro e à sociedade; e a cultura, que é o entendimento da verdade.

Afinal, haverá alguma forma de a psicanálise e os psicanalistas contribuírem para a transformação da violência? Como encarar o potencial de verdade contido na relação da violência com a sobrevivência de culturas e civilizações? Por que algumas sobrevivem e prosperam e outras desaparecem ou se destroem?

Algumas civilizações prosperam e perduram por fundamentar a autoridade sobre atitudes idealistas da mente, com predominância da persuasão e do diálogo. Outras trabalham pela preponderância de Eros sobre Tânatos e aprendem com a experiência: em vez de fazer vistas grossas para os graves problemas que as cercam, decidem enfrentálos e planejam ações de longo prazo, diminuem a onipotência e elaboram o luto pelas suas perdas e limitações.

No Brasil, talvez pudéssemos construir um projeto nacional baseado em sua esportividade, musicalidade, hospitalidade, ou seja, em atividades regidas pelo instinto de vida, e estabelecer um caráter de identificações baseadas nisso.

Poderemos nós, os psicanalistas, supostamente pacifistas e, portanto, com uma intolerância constitucional à violência, apresentar-nos como um contraponto à calamidade e destruição nesta trágica aproximação com a violência?

De acordo com Hanna Segal ${ }^{3,4}$, em dois artigos "Silêncio é o verdadeiro crime" e "A mente do terrorista- fundamentalista: o não aprender da experiência" -, deveríamos primeiro olhar dentro de nós mesmos e, em vez de fazer vistas grossas para a realidade, encarar nosso medo e mobilizar nossas forças contra a violência. Em segundo lugar, pelos nossos conhecimentos da psicologia profunda, poderíamos dar contribuições específicas contra a apatia e a autodecepção presentes em nós e nos outros.

Particularmente, penso que o aprofundamento de estudos sobre uma psicologia psicanalítica da diferença pode revelar novos aportes aos nossos conhecimentos sobre fatores desencadeantes internos de violência.

Por outro lado, convém lembrar que a possibilidade de medidas preventivas contra a violência através da instituição de cuidados de prevenção primária de saúde mental, fundamentados em conceitos da psicanálise e com repercussão sobre a violência, já foi sugerida e discutida em nosso meio 5 .

Apesar de tudo o que dissemos, estamos sujeitos ao risco de chegar ao final com o inquietante sentimento de não saber o que fazer, nem para onde ir. Com certeza, não queremos um governo de selvagens, que só gera selvagens no povo. Mesmo assim, é bom pensar sobre o poema de Brecht, "Sobre a Violência": "A corrente impetuosa é chamada de violenta. Mas o leito do rio que a contém - ninguém chama de violento."

E se nos perguntarmos "Que caminho devemos seguir?", talvez devêssemos responder que não há caminho pior do que o de ficarmos narcisisticamente fixados num refúgio psíquico - como o que se estabelece entre Panchito e Pedro Juan -, dando as costas para a realidade ${ }^{2}$.

Assumiríamos o risco de nos tornarmos tolerantes com Parteignossen ${ }^{6}$, que ficam esculpindo feudos para governá-los a seu bel-prazer, onde a regra do jogo é buscar a verdade quando não se quer a verdade, mas uma vantagem política ${ }^{6}$. E daí esperar que as benevolentes deusas da noite encontrem nosso rastro.

Mas temos que lembrar a imagem inquietante sugerida por Freud: para se ter farinha, é preciso moer os grãos no moinho; só que este pode moer tão devagar que as pessoas morrerão de fome antes de ele fornecer sua farinha. E, assim, retomamos o tema específico da violência e as medidas necessárias para aplacá-la, sem o uso de máscaras de suposta neutralidade.

\section{Referências}

1. Gomes R. Leituras psicanalíticas sobre a violência. In: 21th Congresso Brasileiro de Psicanálise; 2007 maio; Porto Alegre.

2. Gutierrez PJ. O ninho da serpente. São Paulo: Companhia das Letras; 2005.

3. Segal H. Silence is the real crime. Int Rev Psycho-Anal. 1987;14:3-12.

4. Segal $\mathrm{H}$. The mind of the fundamentalist-terrorist: not learning from experience: Hiroshima, The Gulf War and 11 September. In: News \& Events. Annual Issue 2003, The Institute of Psychoanalysis, BPS, London.

5. Busnello E, Machado SP. É possível prevenção primária dos transtornos mentais? Rev Med ATM. 1974;9(1):401-6.

6. Littell J. As benevolentes. Rio de Janeiro: Objetiva; 2007. 